\title{
Caracterização geológica ambiental do Distrito Afonsinho no município de Alto Paraguai - MT
}

\section{Environmental geological characterization of Afonsinho District in the city of Alto Paraguay - MT}

\author{
Deocleciano Bittencourt Rosa ${ }^{1}$, Leonardo Cristian Rocha ${ }^{2}$, Lucelma Aparecida Nascimento ${ }^{3 *}$ \\ e Auberto José Barros Siqueira ${ }^{4}$. \\ ${ }^{1-}$ Professor do Programa de Pós-Graduação em Geografia. Departamento de Geografia da UFMT. Av. Fernando \\ Correa da Costa 2367. Cidade Universitária. Boa Esperança. 78060-900 - Cuiabá, MT. dbrosa@ terra.com.br \\ ${ }^{2-}$ Professor da Universidade Federal de São João del Rei. Campus Tancredo Neves (CTAN). Departamento de \\ Geociências. Avenida Visconde do Rio Preto, s/n (km 2). Colônia do Bengo. 36301-360 - São João del Rei, MG. \\ rochageo@ufsj.edu.br \\ 3*- Doutoranda em Geografia - Laboratoire COSTEL. Université Rennes 2. 6, Av. Gaston Berger. Bloc N, \\ 35000 - Rennes, France. lucelmamt @ yahoo.com.br \\ 4 - Professor da Faculdade de Arquitetura, Engenharia e Tecnologia. Departamento de Engenharia Sanitária e \\ Ambiental. Universidade Federal de Mato Grosso. Av. Fernando Correa da Costa, 2367, Cidade Universitária - \\ Boa Esperança, 78060-900, Cuiabá, MT. ajbsiqueira@gmail.com

\section{* Bolsista de Doutorado Pleno da CAPES.} \\ Recebido, Aceito e Publicado: Novembro /2014
}

Resumo: Este artigo está baseado em estudos geológicos ambientais, realizados na área do Distrito Afonsinho, pertencente ao município de Alto Paraguai, situado na porção Centro-Sul do Estado de Mato Grosso, e drenado pelo rio Paraguai. Aqui estão contidos resultados obtidos em trabalhos de campo e de gabinete, realizados tendo como objetivo maior à questão ambiental dentro da ótica de um levantamento geológico ambiental regional na escala 1:100.000. Dentro deste pensamento foram evidenciados os aspectos mais significativos no que tange a estes estudos, onde foram determinados os recursos naturais, associados com as características climáticas, a geologia regional, a compartimentação geomorfológica, os solos, a hidrografia e a cobertura vegetal. Esses dados estão associados com os resultados dos trabalhos de campo do mapeamento em questão, e de estudos laboratoriais que nos conduziram a edificação de um mapa geoambiental. Estão contidos nesta descrição alguns tópicos que consideramos importantes a fim de ilustrá-la e enfatizá-la.

Palavras Chaves: Geologia ambiental, geossistemas, áreas degradadas

\begin{abstract}
Environmental Geological Characteristics of District Afonsinho in the Municipality of High Paraguay-MT, Brazil.

This article is based on geological environmental studies conducted in the District Afonsinho area, belonging to the municipality of Alto Paraguay, located in the South-Central portion of the state of Mato Grosso, and drained by the Paraguay River. Here results are contained in field work and office, carried out as the biggest environmental issue within the objective viewpoint of a regional environmental geological survey at a scale 1: 100,000 . In this study, we highlighted the importance of the most significant physical characteristics of the studied area which included: climate, regional geology, geomorphology compartmentalization, soils, hydrology and vegetation cover were highlighted. These data, associated with the results of the field mapping and laboratory studies have led us to building a geoenvironmental map. Contained in this description are some topics that we consider important in order to illustrate it and emphasize.
\end{abstract}

Key words: Geoenvironmental, geosystems, abandoned areas. 


\section{Introdução}

Há mais de seis décadas o distrito diamantífero de Afonsinho, localizado no município de Alto Paraguai, numa faixa drenada pela Bacia Hidrográfica do Alto Rio Paraguai, vem tendo suas características naturais desfiguradas diuturnamente pelos intensos processos erosivos, em razão do desmatamento e do mau uso do solo resultantes principalmente, das atividades de garimpagens de diamantes nas margens e no leito do rio Paraguai e de seus afluentes. Com o objetivo de contribuir com o processo de recuperação ambiental das extensas áreas degradadas, bem como para a preservação das terras que ainda estão preservadas, foi realizada a cartografia geológico-ambiental do referido distrito. $\mathrm{O}$ estudo foi realizado no contexto de um levantamento geológico em escala regional, seguido de um mapeamento geológico-ambiental em escala de detalhe. Estes trabalhos foram realizados à sistemática idealizada por Bertrand (1968) em seu Esboço do Modelo de Divisão da Paisagem Física, para determinar as unidades ambientais que hierarquicamente subdivide uma determinada região em taxons maiores, como a Zona, os Domínios e as Regiões Naturais, e em táxons menores, como os Geossistemas ou Sistemas Naturais, os Geofácies e os Geótopos.

\section{Área de Estudo}

O distrito Afonsinho está situado no município de Alto Paraguai, que está localizado geograficamente, nas unidades geomorfológicas conhecidas como Província Serrana (Almeida, 1964) e Planalto de Diamantino (Bittencourt Rosa et al. 1996), na porção Centro-Sul do Estado de Mato Grosso, entre as coordenadas geográficas de latitudes $14^{\circ}$ $30^{\prime}$ e $14^{\circ} 45^{\prime} \mathrm{Sul}$, e longitudes $56^{\circ} 14^{\prime}$ e $56^{\circ} \quad 20^{\prime}$ Oeste de Greenwich, e aproximadamente a $2^{\circ} 15^{\prime}$ à direita do Meridiano Rondon (Figura 1).

O acesso ao município e a área de estudos é possibilitado através da Rodovia Estadual MT-240, que se interliga com a rodovia federal BR-364, que liga Cuiabá, ao Planalto de Diamantino. Uma estrada secundária que parte do setor leste da cidade de Alto Paraguai, comunica a cidade com o Distrito Afonsinho (Figura 2). A área de estudos foi delimitada numa superfície de $84 \mathrm{~km}^{2}$.

Figura 1 - Mapa de localização da área estudada no

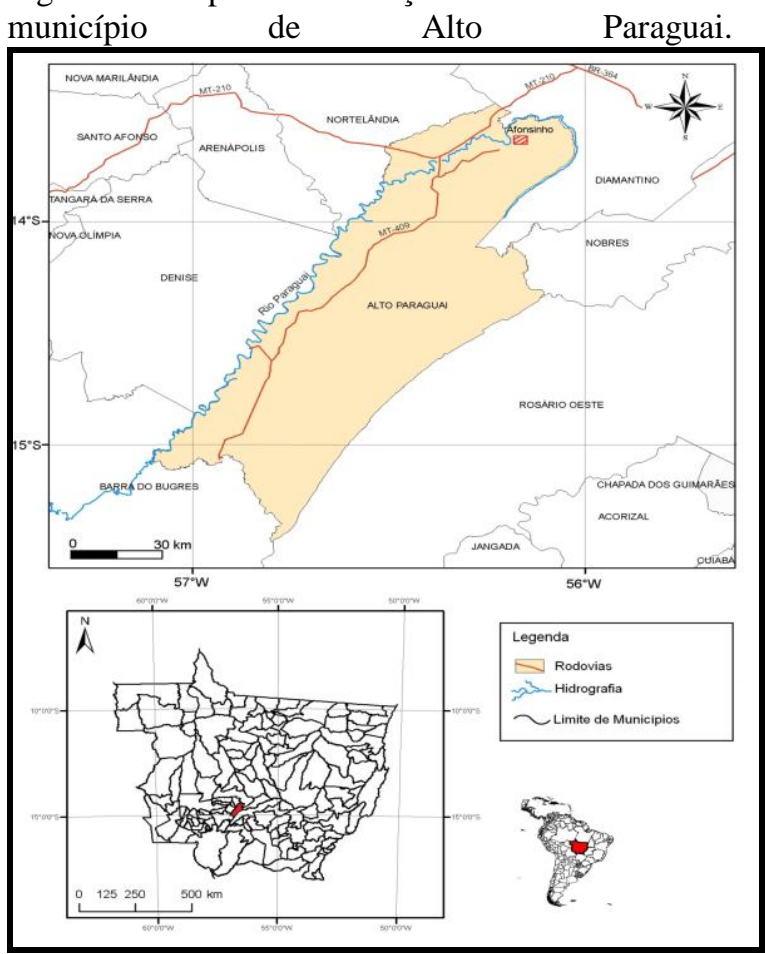

Fonte: Miranda e Amorim (2002).

Existe a possibilidade de acesso por via aérea, porque em Alto Paraguai e no município vizinho de Diamantino, existem pistas de pouso, para aeronaves de pequeno porte, enquanto que o acesso por via fluvial não é recomendável em razão da pouca profundidade do rio Paraguai e de seus afluentes, localmente, mesmo durante a estação chuvosa. 


\section{Procedimentos Metodológicos}

Procedimentos Teóricos - Esta fase de estudos foi levada a efeito nas dependências do Departamento de Geografia do Instituto de Ciências Humanas e Sociais de Universidade Federal de Mato Grosso, com trabalhos iniciais de compilação bibliográfica e depois de observações acuradas de imagens de satélite LANDSAT/TM, bandas 3, 4 e 5, editadas pelo Instituto Nacional de Pesquisas Espaciais - INPE, na escala 1:100.000, em 2008 e comparação com as novas imagens $C B E R S$ (2011).

A carta utilizada como base cartográfica foi o mapa planialtimétrico da Diretoria de Serviço Geográfico - DSG, do Ministério do Exército, na escala 1:100.000, Folha de Serra do Tira Sentido de índice de nomenclatura SD.21-Z-A-IV.

$\mathrm{Na}$ determinação das localizações das toponímias e vias de acesso, foi utilizado como base cartográfica o mapa político e rodoviário do Estado de Mato Grosso, publicado pela Secretaria de InfraestruturaSINFRA na escala $1: 1.500 .000$, no ano de 2012.

Foram utilizadas também nesta fase as cartas temáticas elaboradas pelo Projeto RADAMBRASIL, Folhas SD.21/Cuiabá, na escala 1:1000.000, e respectivamente, a de geologia de Barros et al. (1982), vegetação de Amaral et al. (1982), geomorfologia de Ross e Santos (1982), pedologia de Oliveira et al. (1982), uso exploratório dos solos de Roessing et al. (1982), e também cartas publicadas por Bittencourt Rosa et al. (1996, 2002).

Procedimentos Práticos - Esta parte correspondeu ao levantamento geológicoambiental propriamente dito, e posteriormente ao mapeamento geoambiental, onde foram caracterizados os aspectos geográficos, geomorfológicos, geológicos, geológico-ambientais e ecológicos mais significativos, que se constituem nas bases para o estudo em apreço.

\section{Referencial Teórico}

\section{Dados acerca da Geologia Ambiental}

A geologia ambiental é definida como sendo a ciência que aplica os conhecimentos e princípios da geologia para se entender e solucionarmos os problemas criados pela ocupação e exploração física do meio ambiente, pelas intervenções de natureza humana (Gary, 1974).

As principais áreas abrangidas pela geologia ambiental são: hidrogeologia, topografia, geoquímica, geologia econômica e a engenharia geológica, onde são desenvolvidos estudos acerca de problemas de gerenciamento de águas, do gerenciamento das atividades de recursos minerais, de manejo e gerenciamento de resíduos, construção e transporte, entre outros. Efetivamente a geologia ambiental desloca-se entre vários campos das ciências da terra. As ferramentas de trabalho serão escolhidas segundo Bidone (1992) em função do tipo de abordagem e do domínio espacial.

Os tópicos relativos aos estudos da geologia ambiental entre os diversos campos que são abordados envolvem o homem, o ambiente e os processos geológicos, dentre os quais podemos citar:

a) Fenômenos geológicos de risco: avalanches, terremotos, atividades vulcânicas, processos de erosão acelerada, movimentos de massa (ação de materiais de encostas e fenômenos de enchentes).

b) Modificações do solo impostas pelo homem: alterações da superfície natural por obras civis, as atividades de mineração, alteração na qualidade das águas subterrâneas.

c) Problemas geológicos de disposiçãa de rejeitos: rejeitos sólidos e líquidos, domésticos e industriais. A escolha dos locais para os aterros sanitários.

d) Problemas geológico-ambientais em regiões costeiras: o problema da ocupação do espaço pelo homem, das obras do tipo dique, barreiras, quebra-ondas, moldes, 
guias-correntes que causam mudanças nas características naturais dos processos dinâmicos, provocando mudanças na erosão e sedimentação marinhas. Os problemas de aterro e draga dos mangues. Rejeitos domésticos e industriais nas regiões litorâneas, associados à dinâmica das ondas, correntes e marés.

\section{A degradação ambiental}

Neste trabalho, alguns dados devem ser fornecidos acerca da degradação ambiental no Distrito Afonsinho e suas circunvizinhanças, principalmente em face das atividades garimpeiras, que remontam de mais de 80 (oitenta) anos; atividades estas que já se constituíram num fator importante na ocupação não só do distrito em apreço como também do município de Alto Paraguai como um todo.

Nos últimos 30 anos houve uma queda generalizada nestas atividades, em função das ações fiscalizatórias governamentais federais e estaduais para com o meio ambiente. $\mathrm{O}$ fato é reconhecido regionalmente. Apesar de ainda existirem muitas frentes de trabalhos de garimpagem, pode-se notar em campo um declínio acentuadíssimo, inclusive com a presença de trabalhos de recuperação ambiental de diversos locais realizados pela prefeitura municipal de Alto Paraguai nestes últimos anos.

Desta forma, a partir de estudos nos raros dados bibliográficos relativos à degradação ambiental da área em foco é importante assinalar que, no decorrer da década de 1970, é que tiveram inicio as conversações e estudos mais diretos sobre o meio natural, no nosso País, isso em face aos problemas ambientais vigentes no nosso planeta, e do avanço de alguns países para com a preservação do meio ambiente, porque muitos problemas relativos a impactos ambientais e à degradação ambiental eram sentidos em função do que aconteceu durante as últimas guerras mundiais, e que vem ainda afetando diretamente os seres vivos, com o Brasil sendo um dos mais prejudicados.
Sabemos que o meio ambiente é estudado na Ecologia, que é a ciência que estuda as relações entre os seres vivos e o meio onde eles vivem. Entretanto o meio ambiente pode ter várias conotações. $\mathrm{O}$ que se observa é que a vida se conduz através das trocas que acontecem, às vezes, fora do alcance do homem, e desta maneira o meio ambiente adquire um significado de maior importância. Em termos de Brasil temos o relato de Custódio (1988), que considera que:

"A progressiva execução de uma política
anti-ecológica, visando apenas o
desenvolvimento econômico, sob a
orientação de notórios grupos de
pressão e entidades nacionais e
multinacionais, com a conivência
criminosa de determinados políticos,
administradores, profissionais, técnicos
ou funcionários inescrupulosos, é que
vem contribuindo para a galopante
deterioração da qualidade de vida”.

Ter conhecimento de qualquer coisa e compreender o meio ambiente nas ciências biológicas é estudar a estrutura e a função dos mais diversos componentes de um sistema de interrelações. Todavia nas ciências geográficas além desta idéia, o meio natural é relatado historicamente, e está intimamente atrelado com os aspectos sociais, culturais e econômicos.

Dentro deste pensamento é que Conti e Furlan (1998) descreveram que:

$$
\begin{aligned}
& \text { "O ambiente é como a natureza } \\
& \text { transformada em sua história pelos } \\
& \text { aspectos culturais". }
\end{aligned}
$$

Grande parte dos trabalhos que vem sendo realizados há alguns anos produziram algumas citações a partir de estudos e conceituações, onde as ciências naturais aparecem nos séculos dezesseis a dezenove, e pela concepção positivista que havia na época, sobre a natureza que sobrevive por si mesma e independente totalmente das atividades humanas. Então desta forma é considerado, como ambiente o espaço onde se desenvolvem os seres vivos.

A história da ocupação deste espaço, assim como também as modificações que ocorreram em determinado período e a 
sociedade, faz com que este meio ambiente tenha uma conotação de caráter dinâmico. Portanto, o ambiente é modificado pelas intervenções de natureza humana e o grau de alteração de um espaço, em relação a outro, é avaliado por suas formas distintas de produção ou então pelas diferentes etapas do avanço tecnológico.

\section{Quadro geográfico-geológico}

Clima - O clima da área estudada não é uniforme e podemos caracterizar um tipo climático tropical a estações contrastadas, ou seja, o de número 2 (dois), segundo a classificação para as grandes linhas do clima de Durand Dastès (1968), modificada por Estienne et Godard (1970) e apresentada por Tardy (1986).

O ano está dividido em duas fases diferenciadas, no que se relaciona com as precipitações pluviométricas, e as mesmas correspondem a uma estação chuvosa e outra seca. Nesta variação sazonal podem ser distinguidos seis meses chuvosos e seis meses quentes, com intermediações de extremos quentes a secos. A estação das precipitações pluviométricas tem seu início progressivo no mês de setembro, e se estende até o mês de abril. O período entre os meses de dezembro a março que corresponde ao verão está caracterizado por um acréscimo generalizado nas precipitações e quase $80 \%$ das chuvas caem nesta temporada.

As temperaturas oscilam entre os $28^{\circ} \mathrm{C}$ aos $39^{\circ} \mathrm{C}$ nas duas estações.

Quadro Geológico Regional - A área do distrito Afonsinho e suas adjacências apresenta-se constituída por uma sequência de rochas que evidenciam episódios deposicionais que tiveram lugar desde o Pré-Cambriano Superior (Grupo Alto Paraguai), passando pelo Terciário (Coberturas Detrito-Lateríticas) até as Aluviões Recentes (Barros et al. 1982, Bittencourt Rosa et al. 1996, 2002 e CPRM, 2004).

Grupo Alto Paraguai - Esta unidade litoestratigráfica (Mendes, 1996) foi descrita inicialmente por Almeida (1964), como um conjunto de serras paralelas conhecido como Província Serrana, que compreende da base para o topo as Formações Bauxi, Moenda, Raizama e Diamantino, a partir de estudos posteriores de Barros et al. (1982) e Weska (1996).

A Formação Bauxi apresenta-se constituída por arenitos quartzosos, arcóseos e intercalações subordinadas de argilitos e siltitos. A Formação Moenda engloba paraconglomerados na sua porção basal e são frequentes arenitos da Formação Bauxi.

A Formação Raizama mostra-se constituída por arenitos contendo intercalações de conglomerados e apresentando às estratificações planoparalela, cruzada, marcas de onda e às vezes intensamente dobrada.

No topo do Grupo Alto Paraguai está posicionada a Formação Diamantino em cuja seção basal ocorrem intercalações pronunciadas de siltitos, Figura 2(b), e arcóseos calcíferos, com o topo evidenciando uma composição em folhelhos e siltitos calcíferos, finamente laminados, às vezes maciços com intercalações subordinadas de arcóseo fino a muito fino contendo marcas de onda. Esta unidade é predominante localmente.

Esta sequência de rochas segundo Barros et al. (1982), compreende um amplo arco de concavidade voltada para sudeste, e se apresenta, como um conjunto de serras paralelas com duas direções gerais dominantes: uma NE-SW, separando a Depressão Cuiabana (Ross e Santos, 1982), da do Alto Paraguai, e a outra E-W, limitando a Depressão Cuiabana da Depressão Interplanáltica de Paranatinga.

Coberturas Detrito-Lateríticas ou Lateritas - Estas coberturas estão dispostas em discordância erosiva recobrindo praticamente todas as unidades do Grupo Alto Paraguai. As espessuras podem variar de 0,5 a 3 metros, estando constituídas por detritos eluvionares, coluvionares e aluvionares. Os detritos aluvionares estão relacionados à rede hidrográfica do rio 
Paraguai. As lateritas constituem crostas de óxido de ferro de cor avermelhada escura, e ocorrem maciçamente, ou em oólitos e psólitos, por vezes irregularmente.

Aluviões Recentes - Estão relatadas a Bacia Hidrográfica do Rio Paraguai e seus afluentes localmente. Estas aluviões compreendem um conjunto de sedimentos finos a grossos, areno-argilosos e lateríticos ferruginosos, sendo constituídos por areias, cascalhos quartzosos, cascalhos areníticos e argila, com grande presença de seixos nas calhas e nos leitos do rio Paraguai e seus afluentes, onde se destacam seixos de composição quartzosa, arenítica, silexítica, siltítica, laterítica e argilosa. Esta faixa aluvionar mostra, ás vezes, expressivos sintomas da degradação ambiental. A espessura pode variar de 3 a 8 metros no rio Paraguai, Figura 2(c).

Geomorfologia - A área do distrito Afonsinho está posicionada geomorfologicamente na faixa de contato entre as unidades geomorfológicas conhecidas como Província Serrana e Planalto de Diamantino.

Província Serrana - É a unidade geomorfológica descrita por Almeida (1964), que corresponde a uma extensa área de relevos dobrados de quase $390 \mathrm{~km}$ de comprimento e $40 \mathrm{~km}$ de espessura, que se caracteriza por apresentar uma sucessão de dobras anticlinais e sinclinais alongadas. A partir de estudos anteriores de Ross e Santos (1982), Regis (1993) e Bittencourt Rosa et al. (1996, 2002), e dos trabalhos de campo de mapeamento geológico-ambiental, foi possível estabelecer uma caracterização mais ampla para esta unidade.

Do ponto de vista geológico a Província Serrana está constituída pela sequência de rochas pertencentes aos Grupos Paraguai e Araras estruturadas pela presença de uma sucessão de dobramentos anticlinais erodidos e sinclinais alçadas, Figura 2(d), às vezes, tão fortemente trabalhadas por processos erosivos, a ponto de ocasionar a reversão do relevo.
A Figura 2(c) compreende um conjunto de sedimentos finos a grossos, areno-argilosos e lateríticos ferruginosos, sendo constituídos por areias, cascalhos quartzosos, cascalhos areníticos e argila, com grande presença de seixos nas calhas e nos leitos do rio Paraguai e de seus afluentes localmente. Esta faixa aluvionar mostra, às vezes, expressivos sintomas da degradação ambiental.

Figura 2 - (a) Estrada secundária que liga a cidade de Alto Paraguai ao Distrito Afonsinho; (b) Pacote de siltitos cinzentos arroxeados pertencentes à Formação Diamantino aflorantes no distrito Afonsinho; (c) Detalhe das aluviões no leito e nas margens do rio Paraguai; (d) Panorâmica da unidade geomorfológica Província Serrana ao fundo.
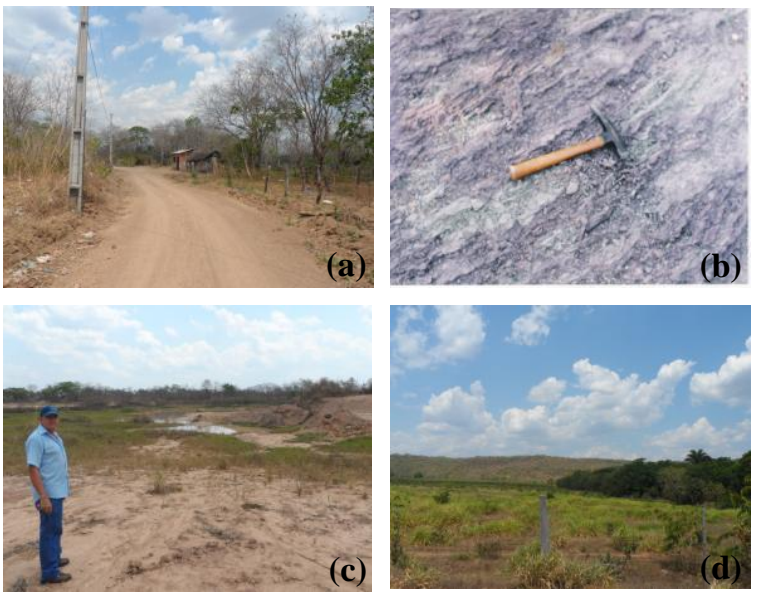

Fonte: (a) Lucelma Aparecida Nascimento, 2012; (b) Deocleciano Bittencourt Rosa, 2013; (c) Auberto José Barros Siqueira, 2013; (d) Lucelma Aparecida Nascimento, 2012.

Planalto de Diamantino - Esta compartimentação geomorfológica foi definida por Bittencourt Rosa et al. (1996), e se posiciona desde as cercanias da Rodovia Federal BR-163 nos limites com o Planalto dos Parecis englobando toda a área da Fazenda São João e circunvizinhanças e o vale do rio Arinos. Se descortina até a localidade de Posto Gil, passando pelo Bairro Novo Diamantino até os pontos mais altos da cidade de Diamantino, e se circunscrevendo numa imensa faixa de aproximadamente $600 \mathrm{~km}^{2}$ das faldas orientais das Serras do 
Tapirapuã e Bocaina, e do flanco ocidental da Serra da Caixa Furada e o vale do Alto Rio Paraguai, Figura 3(a), no município de Alto Paraguai.

Neste local predomina geologicamente as Formações Raizama e Diamantino. Os eventos tectônicos Falha do Pari e a Braquianticlinal do Raizama correspondem às manifestações estruturais que demarcam os limites deste planalto com a Província Serrana.

Solos - A área em apreço está representada pelos seguintes tipos de solos: Solos Concrecionários, Latossolos, Argissolos, Cambissolos, Neossolos Regolíticos e Neossolos Quartzarênicos e Organossolos, Figura 3(b), Dados obtidos a partir de Oliveira et al. 1982, EMBRAPA 1999, 2006, Moreira e Vasconcelos, 2007 e de trabalhos de campo).

Hidrografia - $\mathrm{O}$ distrito Afonsinho é drenado pelo rio Paraguai no sentido NESW, Figura 3(c), e tem seu curso bastante desfigurado em razão das inúmeras frentes de garimpagem em suas margens, onde as catas são abertas para a busca dos diamantes, Figura 3(d). Localmente existe também a retirada do material estéril amontoado, que é aproveitado para a construção civil.

\section{Prancha 2}

Figura 3 - (a) Aspectos do Planalto de Diamantino; (b) Neossolos Quartzarênicos e Organossolos; (c) Faixa de drenagem do rio Paraguai no distrito Afonsinho, ainda com Mata Ciliar conservada; (d) Frentes de garimpos relacionadas ao leito e as margens do rio Paraguai nas cercanias do distrito de Afonsinho.
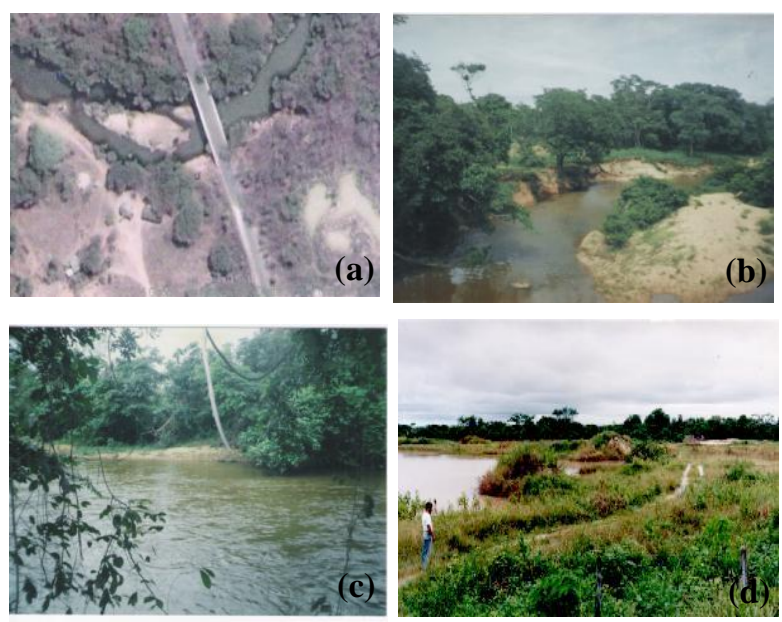

Fonte: (a) Google Earth-Terra Metrics; (b) Deocleciano Bittencourt Rosa, 2013; (c) Lucelma Aparecida Nascimento, 2012; (d) Auberto José Barros Siqueira, 2013.

Vegetação - A área de estudos está caracterizada por 6 (seis) formações vegetais: Cerrado (Savana), com presença de Campo Cerrado (Savana Arbórea Aberta), Campo Sujo (Savana Parque), Campo Limpo (Savana Gramino Lenhosa) Matas (Ciliares e Galerias), Cerradão (Savana Arbórea Densa) e Áreas Desmatadas (Pastagens e Áreas Cultivadas) (Amaral et al. (1982) e Bittencourt Rosa et al. (1996, 2002).

\section{Aspectos Geológicos Ambientais}

\section{Geologia ambiental}

A inter-relação dos estudos geológicos ambientais com a Geomorfologia, e a Ecologia, tanto a relativa aos Ecossistemas, como a Aplicada, podem ser evidenciados para caracterizar uma determinada região no ponto de vista geográfico/ geológico/ ambiental, todavia esses estudos são raros, quando estamos nos referindo a uma escala regional, ou de detalhamento desta região. Desta forma em trabalhos de campo de levantamento geoambiental, foi possível descobrir esta relação, entre alguns tipos de rochas com as formas do relevo, e também com os outros aspectos fisiográficos, que nos levaram a confecção de um mapa geoambiental.

Tomando como base os estudos realizados pelo IBGE (1994) e por Del'Arco et al. (1995), o mapa geoambiental pode ser considerado, como uma base para as avaliações acerca da qualidade ambiental de uma dada região, porque ele caracteriza o meio físico-biótico, onde segundo estes estudiosos anteriormente citados, são postas em prática as ações políticas e as pressões sócio-econômicas, que se constituem nas variáveis examinadas nesta descrição.

Um mapa geoambiental é também considerado por Del'Arco et al. (1995), 
como a representação compartimental de um determinado espaço físico, em função da análise das associações de seus principais constituintes que foram anteriormente, pré-citados, em relação direta com o Esboço do Modelo de Divisão da Paisagem Física de Bertrand (1968), que em sua ordem hierárquica, determina de uma parte, os taxons maiores como: a Zona, o Domínio e a Região Natural, e de outra parte os taxons menores como: o Geossistema ou Sistema Natural, o Geofácies e o Geótopo, como as unidades físicas da paisagem.

Partindo-se então desta sistemática, podemos caracterizar no mapa geoambiental da área do distrito Afonsinho, estas unidades, tendo-se a Região Natural, como a unidade principal. Esta Região Natural está diversificada fisiográficamente e compartimentada em 3 (três) Geossistemas em consonância com os dados de Bertrand (1968) e Bittencourt Rosa et al. (1996, 2002), Figura 4, assim distribuídos:

a) Geossistema com Predomínio da Cobertura Vegetal e Áreas Cultivadas (G.P.CV.AC);

b) Geossistema dos Latossolos, Argissolos, Solos Concrecionários, Cambissolos, Neossolos Regolíticos e Neossolos Quartzarênicos (G.L.A.SC.C.NR.NQ.);

c) Geossistema com Forte Atividade de Natureza Humana e Predomínio de Neossolos Quartzarênicos e Organossolos (G.F.A.NH.P.NQ.O.).
Figura 4 - Mapa geoambiental do distrito de Afonsinho no município de Alto Paraguai.

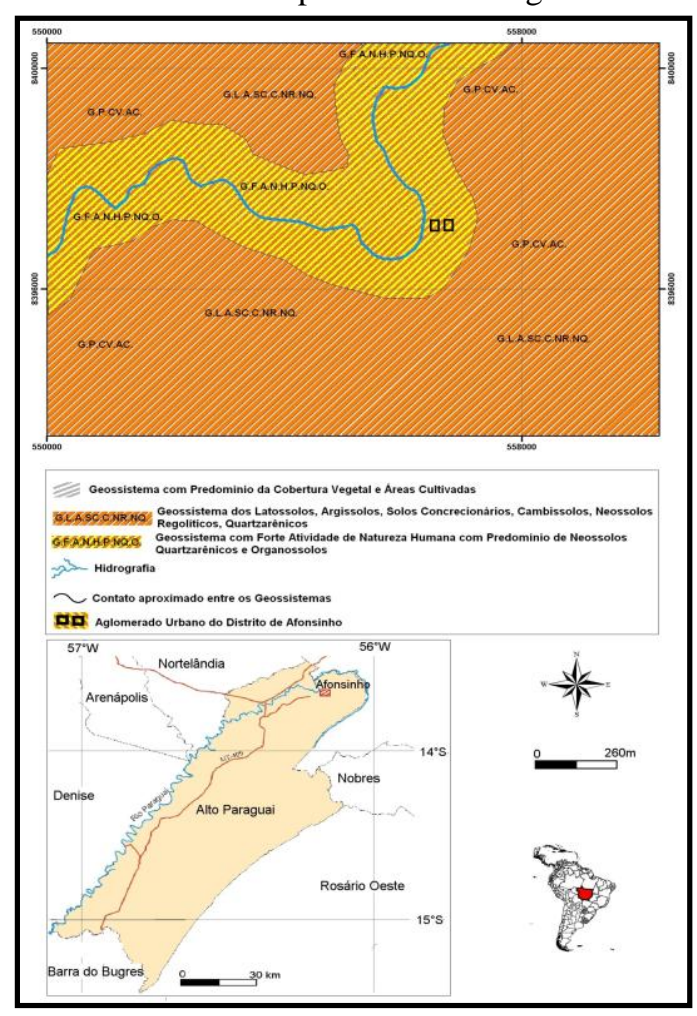

Fonte: IBGE (1975 e Miranda e Amorim, 2002).

Geossistema com Predomínio da Cobertura Vegetal e Áreas Cultivadas

Esta unidade abrange a faixa de cobertura vegetal existente no distrito Afonsinho, isto porque a que foi, e que é desmatada localmente, é considerável, quase que $60 \%$, principalmente, nos vales do rio Paraguai. A representação maior deste geossistema está associada ao local do distrito e as suas cercanias.

Os processos geomorfogenéticos e geoambientais estão interligados com os fatores degradação ambiental, erosão, as atividades garimpeiras e a busca de material de construção, para os mais diferentes trabalhos na construção civil. Os corredores de matas ciliares e galerias, foram os mais atingidos pelos desmatamentos para a garimpagem, assim como aqueles que são possíveis de estarem referidas as áreas desmatadas (pastagens e áreas cultivadas).

Geossistema dos Latossolos, Argissolos, Solos Concrecionários, Cambissolos 
Neossolos Regolíticos e Neossolos e Quartzarênicos

Este geossistema corresponde aos conjuntos de tipos de solos que predominam na área de estudos, onde intercalações dos latossolos, argissolos, solos concrecionários, cambissolos neossolos regolíticos e quartzarênicos podem ser observadas, às vêzes com manchas esparsas em associação com cobertura vegetal e as áreas cultivadas. Frentes de garimpos são comuns neste geossistema.

Concentrações do rejeito dos garimpos (cascalho diamantífero) constituídos por seixos quartzosos, de arenitos, quartzo arenitos, argila, entre outros estão amontoados aleatoriamente, e em certos locais algumas gramíneas se desenvolvem sobre os mesmos e nos arredores, em locais anteriormente desmatados (Figura $5)$.

\section{Geossistema com Forte Atividade de} Natureza Humana e predomínio de Neossolos Quartzarênicos e Organossolos Localmente podem ocorrer neste geossistema algumas áreas úmidas provenientes de represamentos ou de alagamentos na faixa de organossolos, que se constituem em ecossistemas frágeis, tais como as nascentes de água, os açudes e aos terrenos inundados (Figura 5), que ocupam os setores mais baixos da superfície de aplainamento e os depósitos aluvionares, e o assoreamento que se constitui em face dessas atividades sem qualquer acompanhamento técnico.

Os níveis argilosos inferiores e as cheias que ocorrem durante a estação das chuvas, delimitam o comportamento destas áreas, onde estes represamentos são construídos para a reserva de água, para os garimpos (Figuras 5).

Convém ressaltar que a maior parte dos tipos de uso dos solos para estas áreas úmidas, está associada aos aterros das mesmas, o que pode acarretar em suas destruições. Nesta caracterização como geossistema, foram consideradas as áreas recentemente desmatadas e também aquelas preparadas para implantação de cultivos.

Prancha 3

Figura 5 - Áreas de Garimpo.
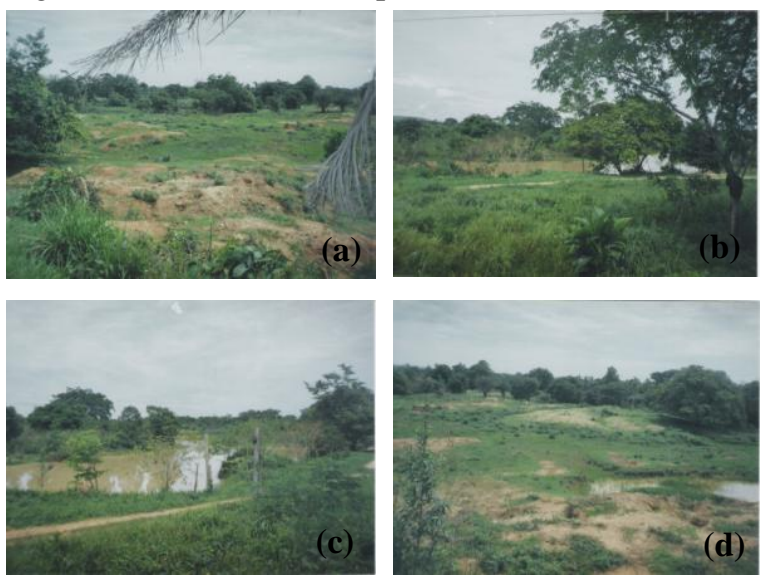

Fonte: 5(a) Auberto José Barros Siqueira, 2013; (b) Lucelma Aparecida Nascimento, 2012; (c) e (d) Lucelma Aparecida Nascimento, 2012.

\section{Considerações Finais}

Esses estudos realizados no distrito Afonsinho e suas vizinhanças vieram demonstrar que esta área apresenta problemas muito sérios no que se relaciona com a questão ambiental, os quais são devidos essencialmente ao uso indevido do solo, aos desmatamentos, e, sobretudo, a atividade garimpeira.

No início da década de 1970, a economia da região em análise se baseava na pecuária extensiva e na atividade extrativa de ouro e diamantes principalmente através de garimpos manuais. Todavia, a partir da década de 70, houve incentivos governamentais para a introdução de pastagens plantadas na região, o que resultou no desmatamento da vegetação nativa em larga escala. No que se refere ao garimpo, houve a introdução da mecanização, através das dragas de sucção e desmonte hidráulico dos cascalhos. A combinação desses dois fatores em uma região de grande fragilidade natural, sem medidas protetoras adequadas, levou ao rápido esgotamento dos recursos naturais que eram a base da economia local, consequentemente, deixando o município 
de Alto Paraguai em uma situação de penúria.

Entretanto, em que pese sua visível decadência, podemos considerar que a garimpagem de diamantes ainda hoje subsiste localmente, alimentada pelo sonho resiliente de encontrar a "pedra grande" nos cascalhos já intensamente retrabalhados. Desse modo, será um grande desafio encontrar atividades alternativas ambientalmente sustentáveis para distrito Afonsinho. Nesse sentido é importante considerar também a extração de minhocas, que se constitui numa outra fonte de renda além dos garimpos, a qual poderia, em tese, se tornar uma forma sustentável, caso ocorra de acordo com orientação técnicas adequadas.

\section{Referências Bibliográficas}

ALMEIDA, F. F. M. de. 1964. Geologia do Centro-Oeste Matogrossense. Boletim da Divisão de Geologia e Mineralogia, (215): 1 - 133, Rio de Janeiro.

AMARAL, D. L.; FONZAR, B. C. e OLIVEIRA FILHO, L. C. de. 1982. Vegetação. As Regiões Fitoecológicas, Sua Natureza E Seus Recursos Econômicos. Folha SD.21/Cuiabá. BRASIL/Ministério das Minas e Energia. Secretaria Geral, Projeto RADAMBRASIL, (Levantamento dos Recursos Naturais, 26), p. 401 - 452, Rio de Janeiro, RJ.

BARROS, A. M.; SILVA, R. H. da.; CARDOSO, O. R. F. A.; FREIRE, F. A.; SOUZA JÚNIOR, J. J. de.; RIVETTI, M.; LUZ, D. S. da.; PALMEIRA, R. C. de. e TASSINARI, C. C. G. 1982. Geologia, Folha SD.21/Cuiabá. BRASIL/Ministério das Minas e Energia. Secretaria Geral, Projeto RADAMBRASIL (Levantamento dos Recursos Naturais, 26), p. 25 - 192, Rio de Janeiro, RJ.

BERTRAND, G. 1968. Paysage et Géographie Physique Globale. Esquisse Méthodologique. "Révue Géographique des Pyrenées et du Sud Ouest”, 39 (3): 249 - 372, Toulouse, France.
BIDONE, E. D. 1992. Curso de Geologia Ambiental. Notas de aulas, Universidade Federal do Rio Grande do Sul, 7 p.

BITTENCOURT ROSA, D.; GARCIA NETTO, L. da R.; PAIVA, D. J. de. e MOSCARDINI, Z. de. O. 1996. "Uma Contribuição aos Estudos Geoambientais e Morfogenéticos na Bacia do Alto Rio Paraguai - MT". Projeto de Pesquisa, Relatório Final, Conselho Nacional de Desenvolvimento Científico e TecnológicoCNPq/Coordenação de Ciências Biológicas e Meio Ambiente-CBMA, Processo $n^{\circ}$ 530416/93-0, 137 p, Brasília, DF.

BITTENCOURT ROSA, D.; NASCIMENTO, L. A.; ALVES, D. de. O.; MACEDO, M.; GARCIA NETTO, L. da. R.; PINTO, S. D. S.; BORGES, C. A.; ROSSETO, O. C.; TOCANTINS, N.; GELA, A.; LOPES dos SANTOS, P e GERALDO, A. C. H. 2002. Um Estudo Geoambiental Comparativo das Características Morfoestruturais e Morfoesculturais nas Áreas das Bacias do Alto Rio Paraguai e do Rio Teles Pires no Estado de Mato Grosso. Projeto de Pesquisa, Relatório Final Fundação de Amparo à Pesquisa do Estado de Mato Grosso-FAPEMAT/Conselho Nacional de Desenvolvimento Científico e TecnológicoCNPq, 319 p, Cuiabá, MT.

BRASIL/CPRM - Companhia de Pesquisa de Recursos Minerais. Serviço Geológico do Brasil. 2004. Geologia e Recursos Minerais do Estado de Mato Grosso. SECMIN - Secretaria de Estado de Indústria e Mineração do Estado de Mato Grosso. Mapa Geológico, Cuiabá, MT.

BRASIL - EMBRAPA - Empresa Brasileira de Pesquisa Agropecuária. 1999. Sistema Brasileiro de Classificação de Solos, 429 p, Brasília, DF.

BRASIL-IBGE - Fundação Instituto Brasileiro de Geografia e Estatístico. 1994. Zoneamento Ecológico-Econômico do Aglomerado Urbano de Goiânia. Secretaria de Planejamento e Desenvolvimento Regional 
SEPLAN/GO, Diretoria de Geociências, Goiânia, GO.

BRASIL/MAPA/EMBRAPA - Ministério da Agricultura, Pecuária e Abastecimento Centro Nacional de Pesquisa de Solos. 2006. Sistema Brasileiro de Classificação dos Solos. $2^{\mathrm{a}}$ Edição. Revisada, 306 p, Rio de Janeiro, RJ.

CONTI, J. B. e FURLAN, S. A. 1998. Geoecologia: o clima, os solos e a biota. In: Geografia do Brasil. Organização. J. L. S. Ross, $2^{\mathrm{a}}$ Edição, Editora Universidade de São Paulo, São Paulo, SP.

CUSTÓDIO, H. B. 1988. Impactos Sociais $e$ Ambientais de Industrialização. In: Modernização e Desenvolvimento do Interior de São Paulo, Editora Universidade Estadual Paulista Júlio de Mesquita Filho-UNESP, Presidente Prudente, SP.

DEL'ARCO, D. M.; DEL'ARCO, J. de. O.; RIOS, A. J. W.; DAMBRÓS, L. A.; NOVAES, A. S. S. e PINTO, J. C. de. A. 1995. Mapa Geoambiental do Estado de Tocantins - Escala 1: 1000.000. In: SIMPÓSIO NACIONAL DE GEOGRAFIA FISICA APLICADA, 6, Goiânia, GO, UFG, Anais do., p. 511 513, Goiânia, GO.

DURAND-DASTES, F. 1968. Climatologie, Encyclopaedia Universalis, 4, p. 618 - 624, Paris, France.

ESTIENNE, P. e GODARD, A. 1970. Climatologie. Armand Colin, Collection U, 365 p, Paris, France.

GARY, S. D. 1974. Pensamientos y Métodos Geográficos $n^{o}$ 3. In: Cultura en los orígenes de la geología española, Edition. "Geography in Spain", 204 p, Espanha.

KER， J. C.; PEREIRA， N. R.; CARVALHO JÚNIOR, W. de. e CARVALHO FILHO, A. de. 1990. Cerrados: Solos, Aptidão e Potencialidade Agrícola. In: SIMPÓSIO SOBRE MANEJO E CONSERVAÇÃO DO SOLO NO CERRADO, Goiânia, GO, Edição Fundação Cargill, p. 1 - 19, Goiânia, GO.
MENDES, J. C. 1996. Elementos de Estratigrafia. Biblioteca de Ciências Naturais. Edição T. A. Queiroz, 567 p.

MIRANDA, L. e AMORIM, L. 2002. Atlas Geográfico do Estado de Mato Grosso. Edição Entrelinhas, cuiabá, MT, $45 \mathrm{p}$.

MOREIRA, M. L. C. e VASCONCELOS, T. N. N. 2007. Mato Grosso SOLOS E PAISAGENS. Edição Entrelinhas, SEPLAN - Secretaria de Estrado de Planejamento e Coordenação Geral, MT, 222 p, Cuiabá, MT.

OLIVEIRA, V. A. de.; AMARAL FILHO, Z. P. de. e VIEIRA, P. C. de. 1982. Pedologia (Levantamento Exploratório dos Solos), Folha SD-21/Cuiabá. BRASIL/Ministério das Minas e Energia. Secretaria Geral, Projeto RADAMBRASIL (Levantamento dos Recursos Naturais, 26), p. 257 - 400, Rio de janeiro, RJ.

REGIS, W. D. E. 1993. Unidades do Relevo. In: IBGE, Recursos Naturais e Meio Ambiente: uma Visão do Brasil, p. 39 - 46, Rio de Janeiro, RJ.

ROESSING, H. M.; NOVAES, J. A. C. de.; MOTTANA, C. E. e MONTORO, R. M. R. 1982. Uso Potencial da Terra, Folha SD.21/Cuiabá, BRASIL/Ministério das Minas e Energia. Secretaria Geral, Projeto RADAMBRASIL, (Levantamento dos Recursos Naturais, 26), p. 453 - 540, Rio de Janeiro, RJ.

ROSS, J. L. S. e SANTOS, L. M. dos. 1982. Geomorfologia, Folha SD. 21/Cuiabá, BRASIL/Ministério das Minas e Energia. Secretaria Geral, Projeto RADAMBRASIL, (Levantamento dos Recursos Naturais, 26), p. 193 - 256, Rio de Janeiro, RJ.

TARDY, Y. 1986. Le Cycle de L'Eau Climats, Paléoclimats et Géochimie Globale. Masson Editeurs, Paris, 338 p.

WESKA, R. K. 1996. Geologia da Região Diamantífera Poxoréu e Áreas Adjacentes, Mato Grosso. Tese de Doutoramento em Ciências, Instituto de Geociências, Universidade de São Paulo, São Paulo, SP, $219 \mathrm{p}$. 